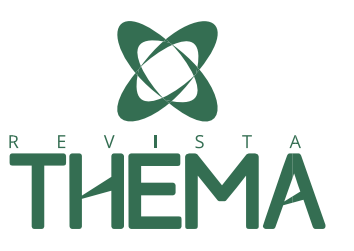

\title{
Redução da qualidade de grãos de soja durante o armazenamento em diferentes condições de umidade e temperatura
}

\section{Reduction of soybean grain quality during storage under different temperature and temperature conditions}

\author{
Anderson Ely ${ }^{1}$
}

\section{RESUMO}

Considerando a importância econômica e alimentícia da cultura da soja no Brasil, e a etapa de armazenamento como fundamental para a garantia de matéria prima de qualidade e para obtenção de melhores preços, 0 objetivo do trabalho foi avaliar a qualidade de grãos de soja armazenados nas temperaturas de 15,25 e $35^{\circ} \mathrm{C}$ com umidades de 12, 15 e $18 \%$ durante o período de 180 dias. As avaliações foram realizadas no tempo zero e a cada 45 dias ao longo do período de armazenamento, onde foram analisados a classificação de grãos, teor de grãos mofados, teor de grãos ardidos, teor de umidade, condutividade elétrica e germinação. Os resultados mostraram que a utilização de temperaturas e umidades mais elevadas de armazenamento, principalmente umidade acima de $12 \%$ provoca alterações nos processos metabólitos dos grãos, reduzindo parâmetros fisiológicos e aumentando a condutividade elétrica, indicando redução da qualidade dos grãos.

Palavras-chave: Glycine max (L.) Merril, resfriamento, classificação, deterioração.

\begin{abstract}
Considering the economic and alimentary importance of the soybean crop in Brazil, and the storage stage as fundamental to the guarantee of quality raw material and to obtain better prices, the objective of the work was to evaluate the quality of soybeans stored at temperatures 15,25 and $35^{\circ} \mathrm{C}$ with 12,15 and $18 \%$ moisture during the 180 day period. The evaluations were carried out at zero time and every 45 days throughout the storage period, where grain classification, molded grain content, burned grain content, moisture content, electrical conductivity and germination were analyzed. The results showed that the use of higher storage temperatures and humidity, especially humidity above $12 \%$ causes changes in the metabolic processes of the grains, reducing physiological parameters and increasing the electrical conductivity, indicating reduction of grain quality.
\end{abstract}

Keywords: soy, temperature, storage, quality

\footnotetext{
${ }^{1}$ UNIPAMPA - Universidade Federal do Pampa, Alegrete/RS - Brasil.
} 


\section{INTRODUÇÃO}

A produção nacional da cultura da soja (Glycine max L. Merril) vem expandido anualmente, devido ao alto teor de proteínas e lipídios, que permite grande utilização na alimentação humana e animal, além de ser a commodity com maior impacto no PIB do setor. Os grãos de soja são fonte de alimento para muitos povos, sejam eles pertencentes a países pobres, emergentes ou desenvolvidos, apresentando utilização nos mais variados ramos da alimentação humana, animal e em sistemas agroenergéticos, devido principalmente a sua composição química, constituída basicamente de proteínas (40\%) de alto valor biológico e baixo custo e lipídios (20\%) de elevada insaturação (Stanojevi et al., 2011). Além disso, os grãos de soja e seus derivados vêm sendo amplamente estudados por ser uma excelente fonte de compostos bioativos, como ácidos fenólicos, flavonoides, isoflavonas, carotenoides e tocoferóis (Dueñas et al., 2012; Kumar et al., 2010).

Diante desse cenário, observamos a necessidade de otimizar o armazenamento que ainda é precário em muitas unidades do país, e na Fronteira Oeste do Rio Grande Sul não é diferente, devendo-se encontrar condições ideais para manter a qualidade inicial da massa de grãos durante o período de armazenado. Dentre os fatores que interferem na qualidade de armazenamento, temperatura e umidade são os principais (FARONI et al., 1998), podendo a técnica de resfriamento artificial ser uma alternativa para o armazenamento. Em geral, a baixa temperatura mantém a qualidade e prolonga a vida útil dos grãos, reduzindo a atividade dos insetos e estendendo seu ciclo biológico, além de conter o crescimento fúngico (Lazzari 1997) e manter o vigor e teor de germinação de sementes. Carvalho \& Silva (1994) constataram o efeito positivo do resfriamento artificial na manutenção das características fisiológicas de sementes de milho e soja.

A temperatura é um dos principais fatores que interferem na qualidade de armazenamento de grãos (Rehman et al., 2002; Reed et al., 2007; Park et al., 2012), sendo que nos últimos anos vem crescendo a utilização da tecnologia de resfriamento artificial em grãos, com o objetivo de preservar a qualidade do produto por períodos mais prolongados e reduzir a deterioração dos grãos. Esta técnica consiste em refrigerar os silos utilizados para armazenamento caracterizados como sistema semi-hermético pois permitem trocas de ar entre o ambiente e o interior da massa de grãos, sendo insuflado ar refrigerado para o interior do silo, pelo sistema de aeração, permanecendo este em funcionamento até a massa dos grãos possuir níveis desejados de temperatura.

A redução da temperatura dos grãos diminui a velocidade das reações bioquímicas e metabólicas dos grãos, pelas quais reservas armazenadas no tecido de sustentação são desdobradas, transportadas e ressintetizadas no eixo embrionário (Santos et al., 2004; Perez-Garcia \& Gonzalez-Benito, 2006; Aguiar et al., 2012), permitindo a manutenção das características inicias de armazenamento dos grãos por períodos mais longos, sendo que alguns trabalhos com uso de resfriamento artificial já foram realizados em grãos de feijão, soja e arroz (Brackmann et al., 2002; Rigueira et al., 2009; Park et al., 2012), porém em condições restritas de armazenamento. Considerando a necessidade de condições seguras de armazenamento para manutenção da qualidade dos grãos, o objetivo no trabalho foi avaliar a qualidade de grãos de soja armazenados ao longo de 180 dias nas temperaturas de 15, 25 e $35^{\circ} \mathrm{C}$ com umidades de 12,15 e $18 \%$. 


\section{MATERIAL E MÉTODOS}

Foram utilizados grãos de soja, produzidos no município de Alegrete, Rio Grande do Sul, Brasil, latitude: 29046'59"S, longitude W 55047'31" e altitude 102m, colhidos mecanicamente e secado até a obtenção das umidades de trabalho desejadas. Acondicionados em sacos de polietileno de 0,2 $\mathrm{mm}$ de espessura de filme plástico, com dimensões de $30 \times 30 \times 30 \mathrm{~cm}$, com capacidade de $1 \mathrm{Kg}$, vedados com máquina Webomatic. Os grãos foram armazenados em sistema semi-hermético com umidade de 12 , 15 e $18 \%$, nas temperaturas de 15,25 e $35^{\circ} \mathrm{C}$, ao longo de 180 dias de armazenamento. Os grãos foram avaliados no início e a cada 45 dias, sendo realizadas análises de classificação, com identificação de grãos mofados e ardidos, teor de umidade, condutividade elétrica e germinação.

\subsection{Classificação de grãos}

A classificação foi realizada de acordo com a Instrução normativa do MAPA No 11, de 15 de março de 2007, que determina o regulamento técnico oficial de classificação de soja, considerando os seus requisitos de identidade e qualidade intrínseca e extrínseca, de amostragem e de marcação ou rotulagem.

\subsection{Teor de grãos mofados}

Foram considerados grãos mofados os grãos ou pedaços de grãos que se apresentam com fungos (mofo ou bolor) visíveis a olho nu.

\subsection{Teor de grãos ardidos}

Foram considerados grãos ardidos os grãos ou pedaços de grãos que se apresentam visivelmente fermentados em sua totalidade e com coloração marrom escura acentuada, afetando o cotilédone (nova redação de acordo com a IN MAPA 37/07);

\subsection{Teor de umidade}

O teor de umidade foi determinado utilizando o método de estufa com circulação de ar, à temperatura de $105 \pm 1^{\circ} \mathrm{C}$, durante 24 horas, em três repetições, de acordo com recomendações da American Society of Agricultural Engineers (ASAE, 2000).

\subsection{Condutividade elétrica}

A condutividade elétrica da água de hidratação foi determinada segundo metodologia do International Seed Testing Association - ISTA (2008), onde foram contadas 4 repetições de 25 grãos, pesados e imersos em $75 \mathrm{~mL}$ de água deionizada (em becker de $250 \mathrm{~mL}$ ), colocadas em germinador regulado para a temperatura constante de $20^{\circ} \mathrm{C}$, por $24 \mathrm{~h}$, e as soluções foram agitadas suavemente e a condutividade elétrica foi determinada com condutivímetro sem filtragem da solução, sendo os resultados serão expressos em $\mu \mathrm{S} . \mathrm{cm}^{-1} \cdot \mathrm{g}-1$. 


\subsection{Teor de germinação}

O teste de germinação foi realizado em quatro repetições de 50 sementes, em rolo de papel toalha, em germinador regulado a $25^{\circ} \mathrm{C}$, embebido em água na quantidade de 2,5 vezes o peso do substrato seco, visando adequado umedecimento, com as contagens feitas no $7^{\circ}$ dia após a semeadura, seguindo as Regras para Análise de Sementes (Brasil, 2009), e os resultados expressos em percentagem pela média das repetições.

\subsection{Análise estatística}

Os resultados foram submetidos à análise de variância ANOVA, a 5\% de probabilidade para as variáveis utilizando software SAS INSTITUTE (2002).

\section{RESULTADOS E DISCUSSÃO}

Os resultados de classificação de grãos de soja apresentados na Tabela 1 indicam que os grãos de soja aos 45 dias de armazenamento apresentavam-se como dentro do padrão básico de comercialização de acordo com IN MAPA 11 de 2007 nas umidades de 12 e 15\% nas três temperaturas, porém os grãos com $18 \%$ de umidade já foram classificados como Fora do Padrão. $\mathrm{Na}$ temperatura de $35^{\circ} \mathrm{C}$ no tempo de 90 dias de armazenamento os grãos com umidade de $15 \%$ foram classificados como Fora do Padrão, e os grãos com umidade de $12 \%$ permaneceram ao longo de todo o período dentro do padrão básico de comercialização, indicando que está umidade é segura para armazenamento nestas condições, mesmo em temperatura elevada. Nas temperaturas de 15 e $25^{\circ} \mathrm{C}$ os grãos aos 180 dias na umidade de $15 \%$ foram classificados como Fora do Padrão, permanecendo como Padrão básico apenas na umidade de $12 \%$ ao longo de todo o período. Os resultados estão de acordo com Alencar et al., (2009), para comercialização de soja como dentro do Padrão Básico, é possível armazenar, durante 180 dias, grãos com teor de água de até 14,8\% nas temperaturas de 20 e $30^{\circ} \mathrm{C}$.

De acordo com Paraginski et al. (2015), a redução da temperatura dos grãos diminui a velocidade das reações bioquímicas e metabólicas dos grãos, pelas quais reservas armazenadas no tecido de sustentação são desdobradas, transportadas e ressintetizadas no eixo embrionário permitindo a manutenção das características inicias de armazenamento dos grãos por períodos mais longos. 0 armazenamento seguro mantém os aspectos qualitativos e quantitativos dos grãos, proporcionando condições desfavoráveis ao desenvolvimento de insetos, roedores e microrganismos. A predição da deterioração qualitativa em grãos, segundo Tang et al. (1999) é de grande importância, uma vez que se costuma armazenar de um ano para o outro, e o tempo de armazenamento seguro é dependente da relação quantitativa entre taxa de deterioração, qualidade e condições de armazenagem dos grãos. 
Tabela 1. Classificação de grãos de soja armazenados nas umidades de 12,15 e $18 \%$ e nas temperaturas de 15,25 e $35^{\circ} \mathrm{C}$ ao longo do período de 180 dias de armazenamento.

\begin{tabular}{|c|c|c|c|c|c|c|}
\hline \multicolumn{2}{|c|}{ Condições de armazenamento } & \multicolumn{5}{|c|}{ Tempo de armazenamento (dias) } \\
\hline $\begin{array}{c}\text { Umidade } \\
\text { (\%) }\end{array}$ & $\begin{array}{c}\text { Temperatura } \\
\left({ }^{\circ} \mathrm{C}\right)\end{array}$ & 0 & 45 & 90 & 135 & 180 \\
\hline \multirow{3}{*}{12} & 15 & Padrão básico & Padrão básico & Padrão básico & Padrão básico & Padrão básico \\
\hline & 25 & Padrão básico & Padrão básico & Padrão básico & Padrão básico & Padrão básico \\
\hline & 35 & Padrão básico & Padrão básico & Padrão básico & Padrão básico & Padrão básico \\
\hline \multirow{3}{*}{15} & 15 & Padrão básico & Padrão básico & Padrão básico & Padrão básico & Fora do padrão \\
\hline & 25 & Padrão básico & Padrão básico & Padrão básico & Padrão básico & Fora do padrão \\
\hline & 35 & Padrão básico & Padrão básico & Fora do padrão & Fora do padrão & Fora do padrão \\
\hline \multirow{3}{*}{18} & 15 & Padrão básico & Fora do padrão & Fora do padrão & Fora do padrão & Fora do padrão \\
\hline & 25 & Padrão básico & Fora do padrão & Fora do padrão & Fora do padrão & Fora do padrão \\
\hline & 35 & Padrão básico & Fora do padrão & Fora do padrão & Fora do padrão & Fora do padrão \\
\hline
\end{tabular}


Os resultados do teor de grãos mofados armazenados nas umidades de 12, 15 e $18 \%$ nas temperaturas de 15,25 e $35^{\circ} \mathrm{C}$ (Figura 1 ) indicam que com umidade de $12 \%$ o teor de mofados permaneceu baixo, garantindo assim a tipificação dentro do Padrão Básico de comercialização. $\mathrm{Na}$ umidade de $15 \%$ o teor de grãos mofados aos 90 dias na temperatura de $35^{\circ} \mathrm{C}$ foi próximo a $10 \%$, resultando na tipificação como Fora do Padrão Básico, sendo que aos 135 dias os valores foram superiores a $15 \%$ de grãos mofado. Ao final de 180 dias de armazenamento, na temperatura de 15 , 25 e $35^{\circ} \mathrm{C}$, os valores encontrados foram próximos a 20,40 e $80 \%$, respectivamente, indicando níveis elevados de grãos mofados na amostra. Nos grãos armazenados com umidade de $18 \%$, condições essa em que ocorre a colheita e o direto armazenamento, sem a realização de secagem, aos 45 dias nas temperaturas de 15 e $25^{\circ} \mathrm{C}$ o teor de grãos mofados era superior a $15 \%$ e na temperatura de $35^{\circ} \mathrm{C}$ era superior a 40\%, resultando em grãos tipificados como Fora do Padrão, sendo que aos 135 dias de armazenamento nas três temperaturas de armazenamento $100 \%$ dos grãos estavam mofados.

A presença de grãos mofados na amostra é de acordo com Sravanthi et al., (2013) provoca pelo desenvolvimento de fungos em grãos armazenados úmidos, sendo responsável pela deterioração dos grãos. Trabalho realizado por Alborch et al. (2011) em grãos de milho concluíram que para os fungos de pós-colheita Aspergillus niger e Aspergillus carbonarius a temperatura de desenvolvimento foi na faixa de 15 a $35^{\circ} \mathrm{C}$, onde o desenvolvimento de fungos possibilita a maior formação de micotoxinas, que estão relacionadas com a segurança alimentar do consumo do produto. Contaminações por micotoxinas tornam os grãos impróprios para alimentação humana e animal, afetando negativamente a segurança alimentar, devido ao consumo de altas doses de aflatoxina levar a aflatoxicose que pode resultar em doenças agudas e até mesmo a morte (Zain, 2011).

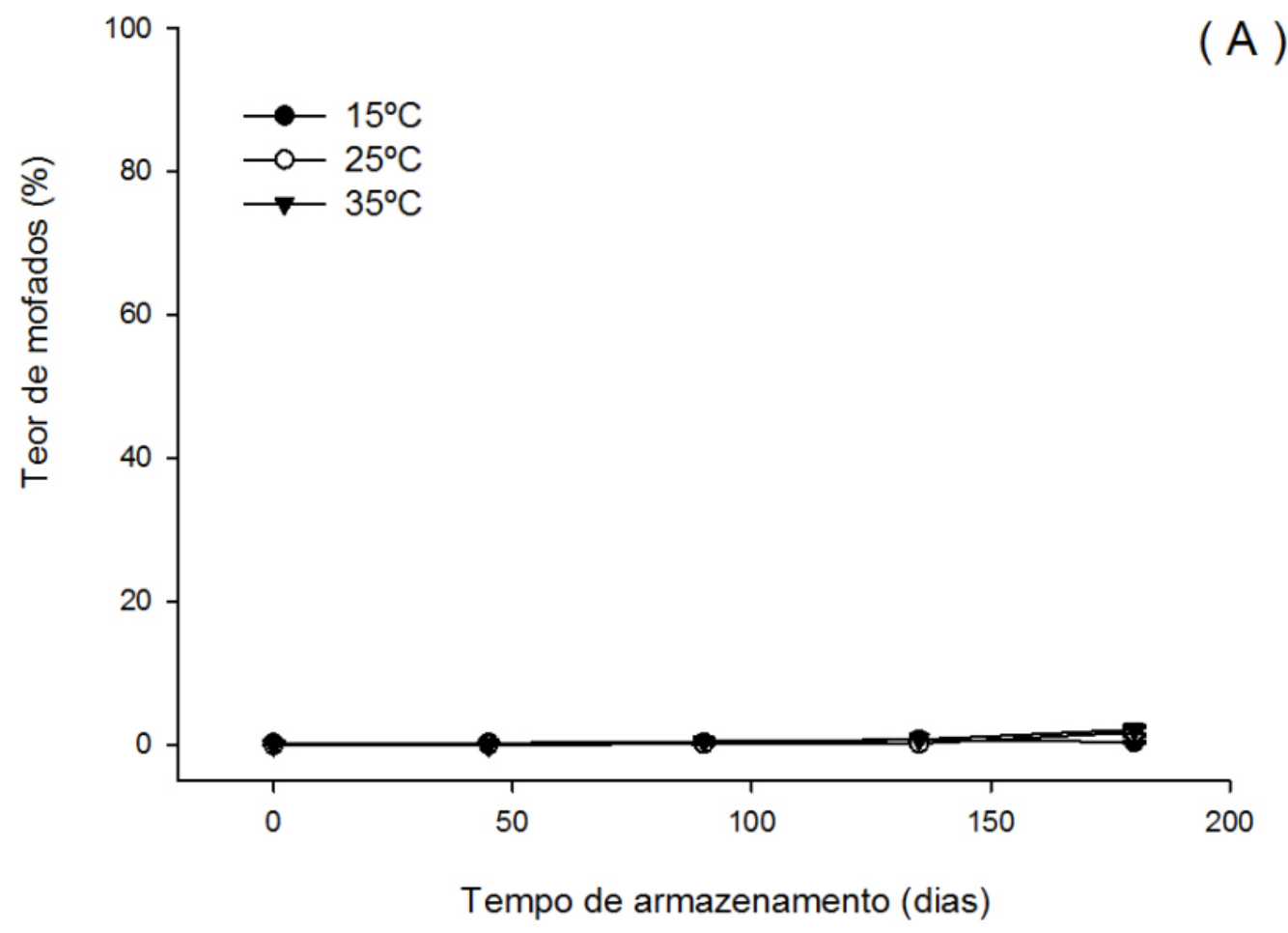



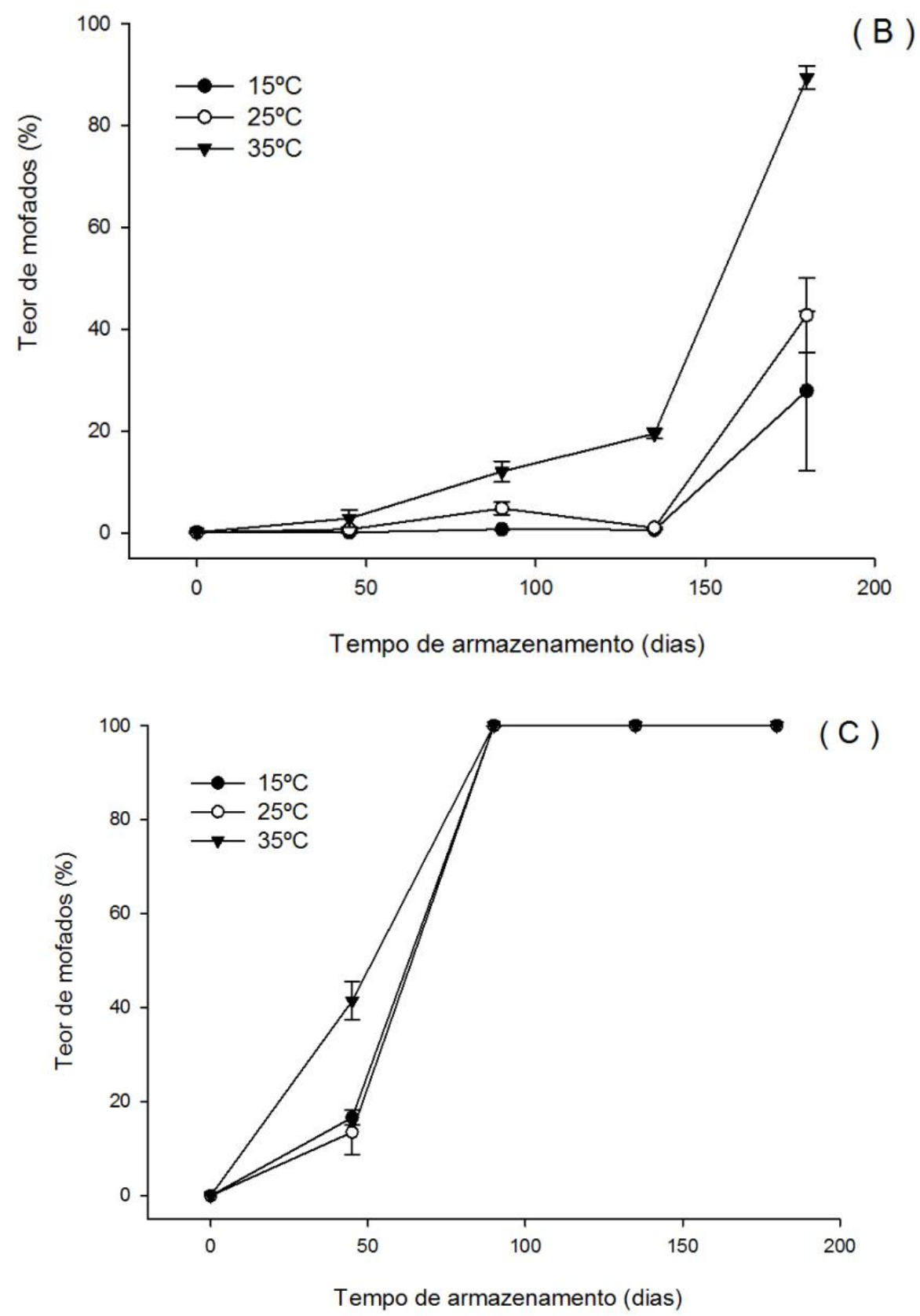

Figura 1. Teor de grãos mofados (\%) grãos de soja armazenados nas umidades de $12 \%$ (A), $15 \%$ (B) e $18 \%$ (C) nas temperaturas de 15,25 e $35^{\circ} \mathrm{C}$ durante 180 dias.

O teor de grãos ardidos (Figura 2) caracterizados pelos grãos ou pedaços de grãos que se apresentam visivelmente fermentados em sua totalidade e com coloração marrom escura acentuada, afetando o cotilédone indicam que houve interferência de processos fermentativos nos tratamentos avaliados. Nos grãos armazenados com umidade de $12 \%$ os valores permaneceram próximos a zero, entretanto nos grãos armazenados com umidade de $15 \%$, aos 45 dias na temperatura de $35^{\circ} \mathrm{C}$ o teor de grãos ardidos foi próximo a $2,0 \%$, e na umidade de $18 \%$ no mesmo período os valores foram próximos a $0,5,1,0$ e 2,0\% nas temperaturas de 15,25 e $35^{\circ} \mathrm{C}$, respectivamente. Nos grãos com umidade de $18 \%$, após aos 135 e 180 dias os valores zero, pois houve a formação de grãos mofados (Figura 1), e de acordo com a IN MAPA No 11 de 2007, este é considerado um defeito mais grave, sendo, portanto, todos classificados como mofados.

A formação de grãos ardidos está relacionada a vários fatores, como a ocorrência de elevada quantidade de chuva na época de colheita, bem como condições inadequadas de armazenamento. A 
ocorrência de grãos ardidos sempre foi atribuída ao processo fermentativo, porém esse processo não forma compostos pigmentados, assim tem-se algumas suposições sobre fatores que podem estar relacionados à ocorrência desses grãos, como: processo respiratório, atividade enzimática, oxidação de carotenoides e atividade bacteriana. Acredita-se que a presença de umidade dos grãos e temperaturas elevadas pode acelerar a atividade enzimática das enzimas degradadoras de lipídios que desestruturam a membrana celular, causando o escurecimento dos cotilédones dos grãos, sendo a polifenoloxidase (PPO) a principal enzima envolvida no processo de escurecimento enzimático, que causa uma oxidação de compostos fenólicos, sendo que o produto inicial da oxidação é a quinona, que forma pigmentos escuros após ser condensado, chamado de melanina, sendo dependente de enzima. A formação de grãos ardidos é um problema na comercialização dos grãos, e isto se intensifica ainda mais no processamento agroindustrial, pois o resultado desses grãos dificulta os processos de beneficiamento e industrialização, reduzindo a qualidade de produtos derivados e aumentado os custos operacionais.
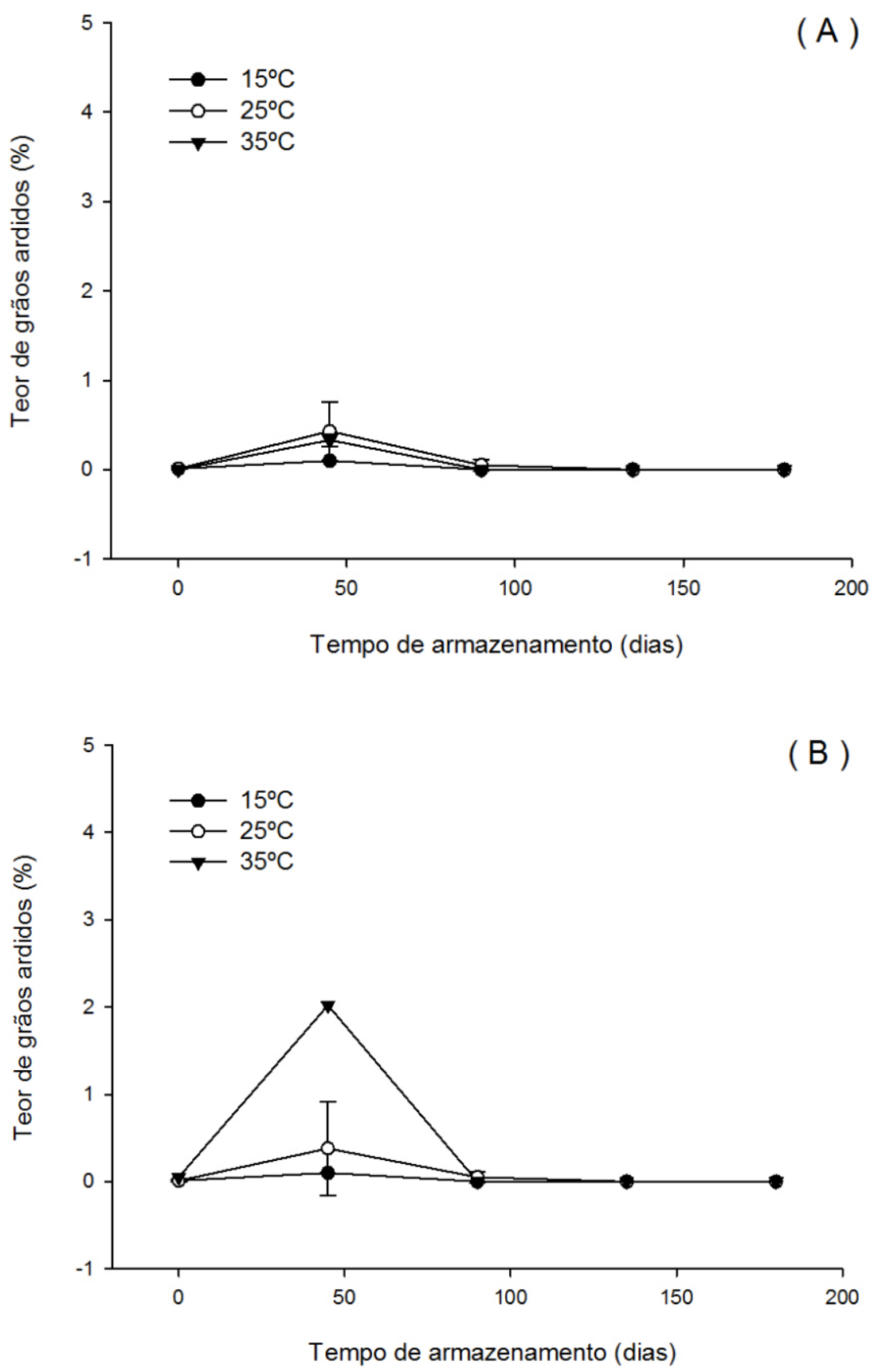


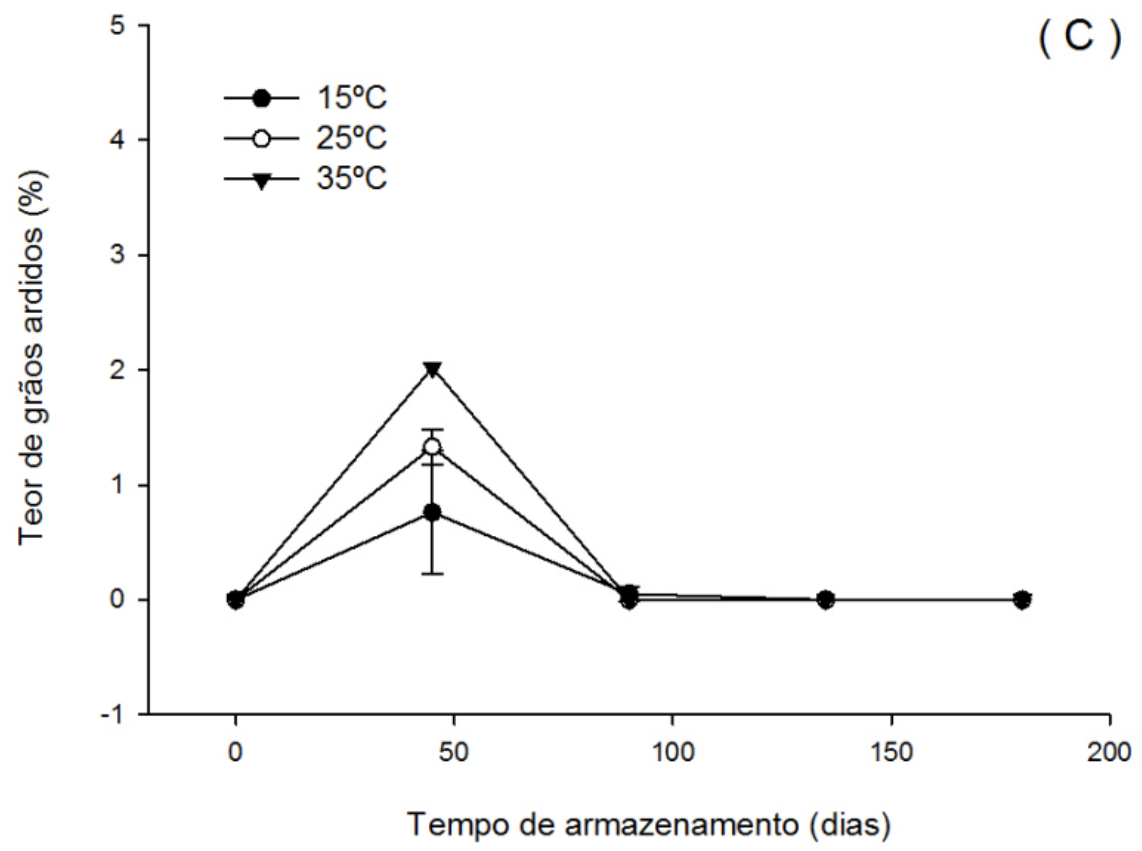

Figura 2. Teor de grãos ardidos (\%) de grãos de soja armazenados nas umidades de $12 \%(\mathrm{~A}), 15 \%$ (B) e $18 \%$ (C) nas temperaturas de 15,25 e $35^{\circ} \mathrm{C}$.

Na Figura 3 são apresentados os resultados do teor de umidade, parâmetro muito importante para a manutenção da qualidade dos grãos durante o armazenamento. Os resultados indicam na umidade de $12 \%$ os valores ao final do período de 180 dias foram de 10,35, 10,38 e 8,30\%, respectivamente nas temperaturas de 15,25 e $35^{\circ} \mathrm{C}$. Na umidade de $15 \%$ os valores variaram de 15,37 a $12,34 \%$ na temperatura de $15^{\circ} \mathrm{C}$, de 15,37 a $12,70 \%$ na temperatura de $25^{\circ} \mathrm{C}$ e de 15,37 a $9,35 \%$ na temperatura de $35^{\circ} \mathrm{C}$. Já na umidade de $18 \%$ os teores variaram de 18,30 a $19,50 \%$ na temperatura de $15^{\circ} \mathrm{C}$, de 18,30 a $20,50 \%$ na temperatura de $25^{\circ} \mathrm{C}$, e de 18,30 a 20,50 na temperatura de $35^{\circ} \mathrm{C}$. Os resultados estão de acordo com Paraginski et al. (2015), que ao avaliar grãos de milho armazenados nas temperaturas de $5,15,25$ e $35^{\circ}$ obteve redução no teor de umidade na temperatura de $35^{\circ} \mathrm{C}$ de $14,31 \%$ no início do armazenamento para 7,79\% ao final de 12 meses.

A redução do teor de água dos grãos observada nos grãos armazenados na temperatura de $35{ }^{\circ} \mathrm{C}$ é resultado do equilíbrio higroscópico dos grãos com as condições do ambiente de armazenamento. Quando a pressão de vapor do grão é maior que a do ar circundante, ocorre o fenômeno de dessorção havendo transferência de vapor de água para o ar reduzindo, desta forma, a umidade dos grãos (Silva et al., 1995), sendo que vários fatores interferem no equilíbrio higroscópico de acordo com Carneiro et al. (2005), como composição química dos grãos, integridade física, estado sanitário, gradientes termo hídricos e operações de pós-colheita, dentre os quais a secagem e o armazenamento são as mais importantes. O aumento da umidade nos grãos armazenados com 18\% de umidade, estão de acordo com Alencar et al., (2009), que afirmaram que a respiração dos grãos é mais intensa a medida em que se tem teores de água elevados, embora a temperatura, a umidade relativa e o estado de conservação, também influenciem o metabolismo dos grãos, os autores ressaltam que a água produzida durante o processo respiratório aumenta o teor de água do produto que, por sua vez, intensifica o desenvolvimento e a taxa respiratória da microflora. 

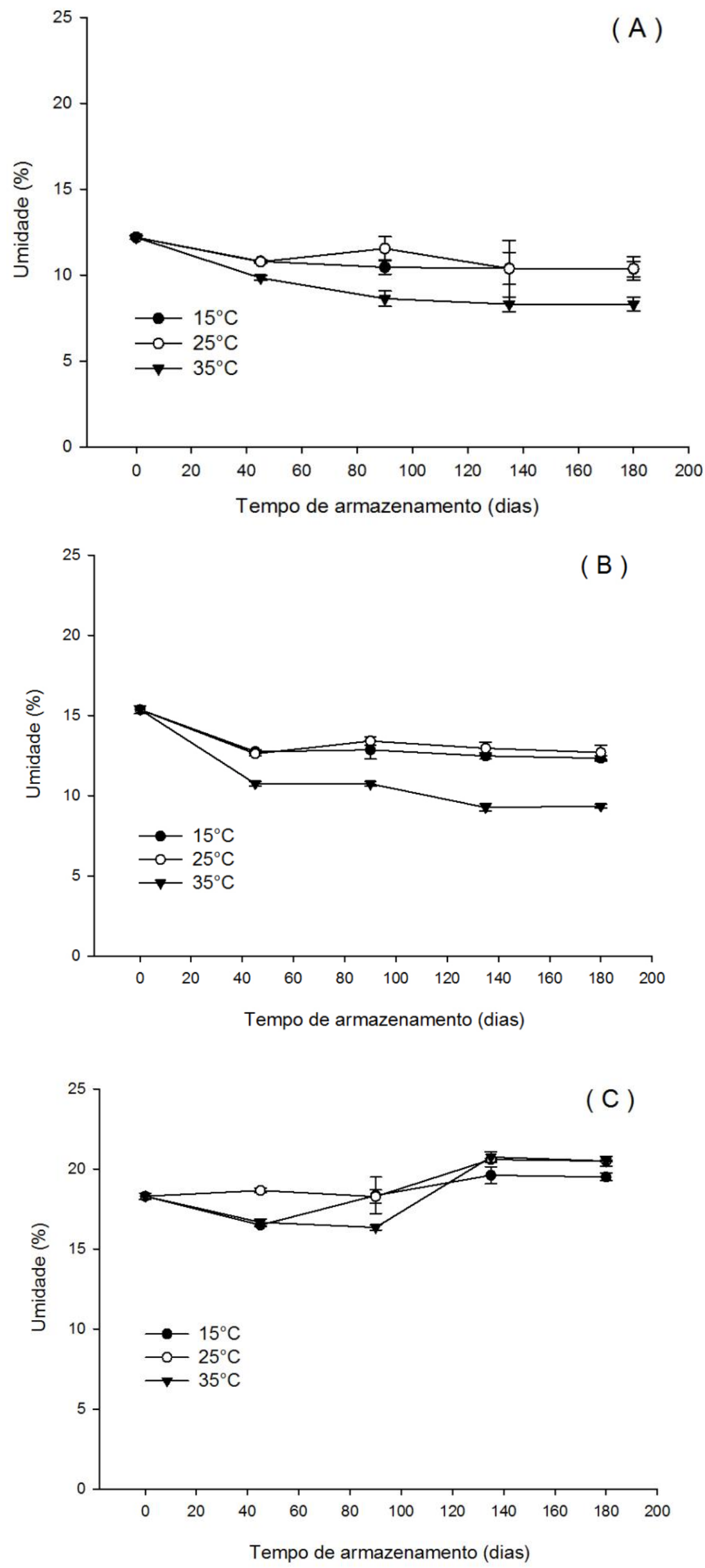

Figura 3. Teor de umidade (\%) de grãos de soja armazenados nas umidades de $12 \%$ (A), $15 \%$ (B) e $18 \%$ (C) nas temperaturas de 15,25 e $35^{\circ} \mathrm{C}$ durante 180 dias 
A condutividade elétrica aumentou ao longo do período de armazenamento em todas as condições avaliadas (Figura 4), sendo que as alterações foram mais intensas nas temperaturas e umidades mais elevadas. Os incrementos mais intensos foram observados aos 45 dias de armazenamento nos grãos armazenados com teores de umidade de 15\% (Figura 4B) e 18\% (Figura 4C) na temperatura de $35^{\circ} \mathrm{C}$, onde a condutividade aumentou de 69,98 para 284 e $335 \mu \mathrm{S} . \mathrm{cm}-1 . \mathrm{g}-1$, respectivamente. Os resultados estão de acordo com Faroni et al. (2009), que avaliou a qualidade de grãos de soja armazenados em silo tipo bolsa em três camadas (superior, intermediária e inferior), e observou aumento significativo da condutividade elétrica da soja com 17,4\% de teor de água em decorrência da interação entre camadas do silo tipo bolsa, sendo que o aumento ocorreu principalmente a partir do terceiro mês de armazenamento, e essa tendência foi observada nas três camadas do silo. Segundo Costa et al. (2010) e Faroni et al. (2005), a leitura da condutividade elétrica pode ser utilizada para avaliar o vigor pois está relacionada com a quantidade de íons lixiviados na solução e a integridade das membranas celulares sendo que membranas desestruturadas e danificadas, resultado do armazenamento incorreto, elevam o valor da condutividade elétrica e, em contrapartida, reduzem o vigor dos grãos e sementes.
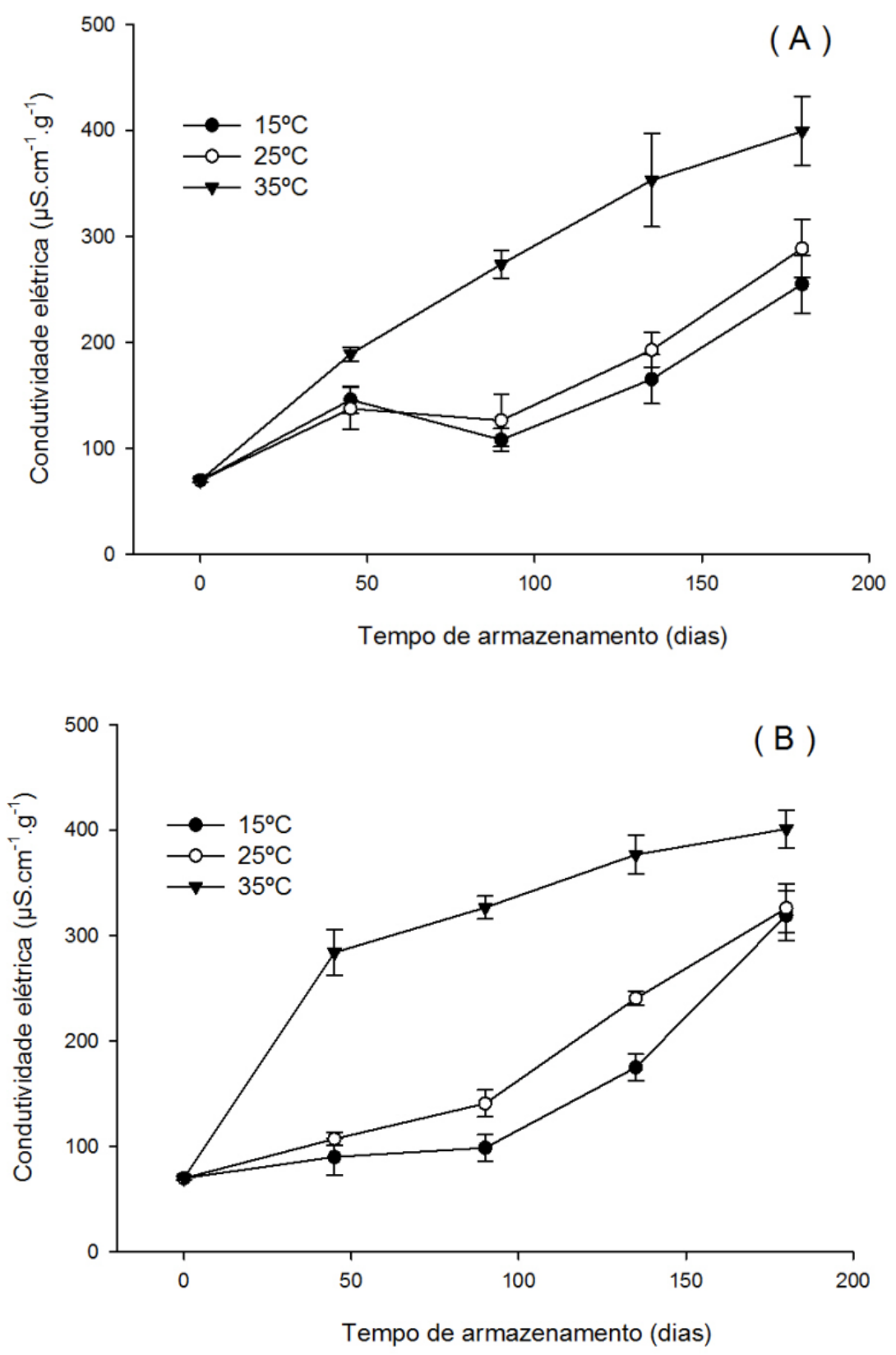


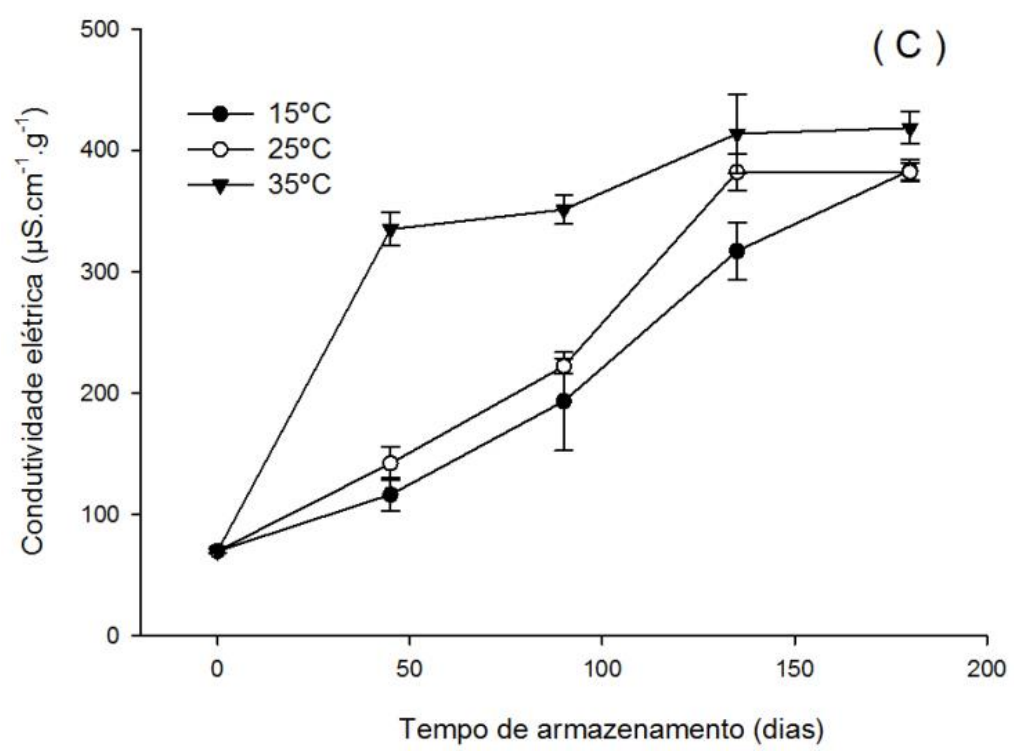

Figura 4. Condutividade elétrica de grãos de soja armazenados nas umidades de $12 \%$ (A), $15 \%$ (B) e $18 \%$ (C) nas temperaturas de 15,25 e $35^{\circ} \mathrm{C}$ durante 180 dias.

Os resultados de germinação apresentados na Figura 5 indicam que ocorreu uma redução do teor de germinação ao longo do período de armazenamento em todos os tratamentos realizados. Na umidade de $12 \%$ (Figura $5 \mathrm{~A}$ ) a maior redução ocorreu na temperatura de $35^{\circ} \mathrm{C}$, onde aos 90 dias os teores já eram de 0,0\%, e nas temperaturas de 15 e $25^{\circ} \mathrm{C}$, ao final de 180 dias os valores foram de 54,5 e $33,3 \%$, respectivamente. Na umidade de $15 \%$ (Figura 5B), na temperatura de $35^{\circ} \mathrm{C}$ aos 45 dias os valores de germinação foram $0,0 \%$ e nas temperaturas de 15 e $25^{\circ} \mathrm{C}$ os valores chegaram a $0,0 \%$ aos 180 e 135 dias, respectivamente. Na umidade de 18\% (Figura 5C) os valores chegaram a 0,0\% aos 45, 90 e 135 dias, nas temperaturas de 35,25 e $15^{\circ} \mathrm{C}$, respectivamente.

Os resultados estão de acordo com trabalhos realizados por Rodriguez et al. (2004), que ao avaliar o efeito da armazenagem hermética no teor de germinação, os autores também verificaram nos grãos de milho com umidade de 14,8 e 19,5\%, decréscimos na germinação após 153 dias de armazenamento para as duas umidades, entretanto a redução foi mais acentuada nos grãos com maior teor de umidade. Segundo Paraginski et al., (2015), a redução do teor de germinação dos grãos decorre das alterações que ocorrem na estrutura das membranas dos grãos sendo que, quando a temperatura e a umidade dos grãos são elevadas, as alterações são mais significativas resultando em perda da qualidade final do produto em curtos períodos de tempo.

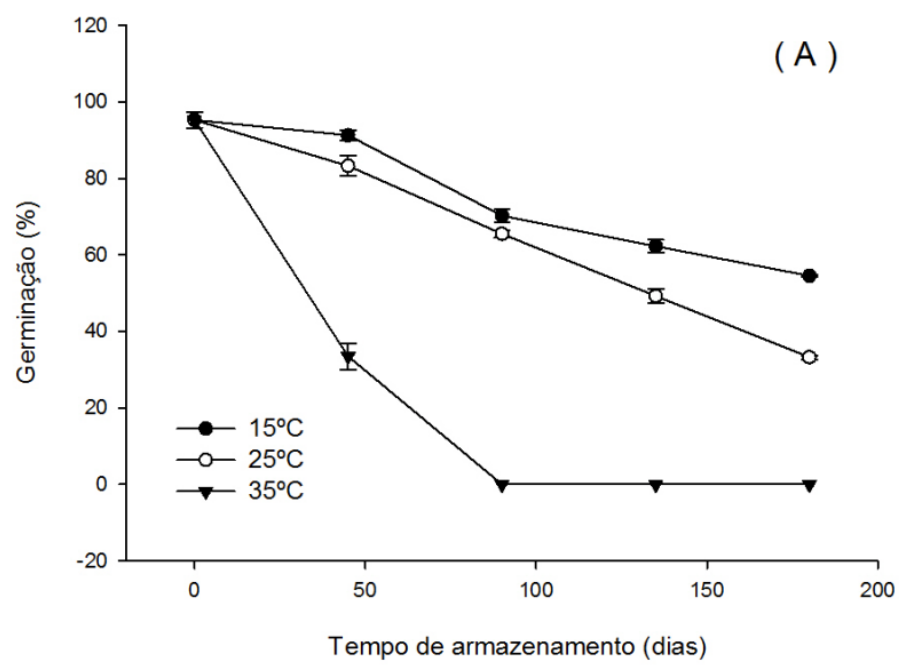



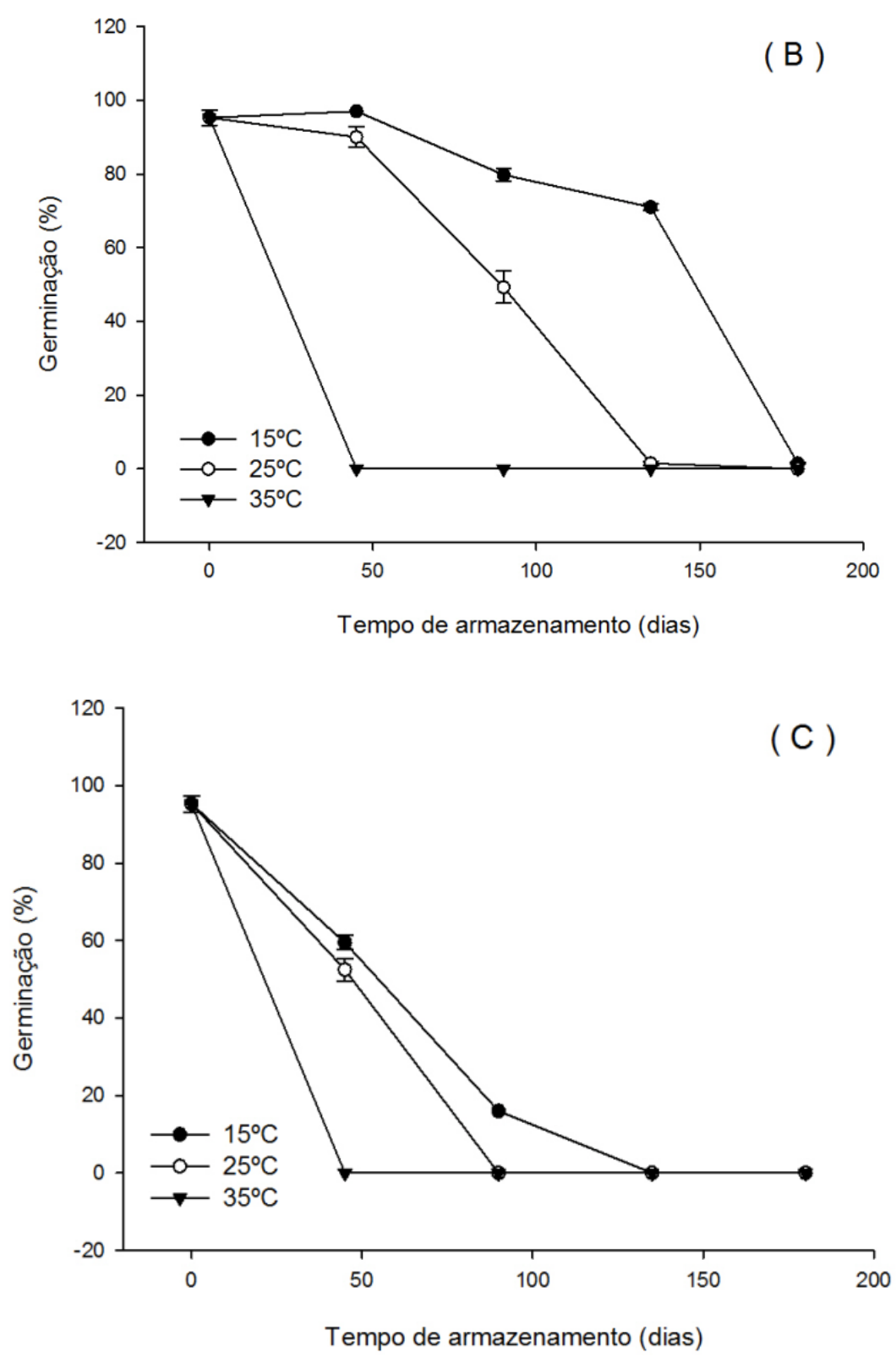

Figura 5. Teor de germinação de grãos de soja armazenados nas umidades de 12\% (A), 15\% (B) e 18\% (C) nas temperaturas de 15,25 e $35^{\circ} \mathrm{C}$ durante 180 dias.

\section{CONCLUSÕES}

1. Os resultados indicam ser possível armazenar grãos de soja na umidade de $12 \%$ nas temperaturas de 15,25 e $35^{\circ} \mathrm{C}$ sem alterar a tipificação final do produto, e na umidade de $15 \%$ até 135 dias nas temperaturas de 15 e $25^{\circ} \mathrm{C}$. Na umidade de $18 \%$ já aos 45 dias, nas três temperaturas $(15,25$ e $\left.35^{\circ} \mathrm{C}\right)$, os grãos foram classificados como Fora do Padrão.

2. O teor de grãos mofados intensifica-se muito nas umidades de 15 e $18 \%$ nas temperaturas de 15 , 25 e $35^{\circ} \mathrm{C}$, tornando-se um risco o consumo e a utilização industrial desses grãos, porém novos estudos precisam ser realizados para avaliação desse risco toxicológico.

3. A utilização de temperaturas e umidades mais elevadas de armazenamento, principalmente umidade acima de $12 \%$ provoca alterações nos processos metabólitos dos grãos, reduzindo parâmetros fisiológicos e aumentando a condutividade elétrica, que indicam problemas na qualidade dos grãos. 


\section{AGRADECIMENTOS}

Gostaríamos de agradecer ao CNPq (Conselho Nacional de Desenvolvimento Científico e Tecnológico), SCT-RS (Secretaria da Ciência, Inovação e Desenvolvimento Tecnológico do Estado do Rio Grande do Sul), a Fapergs (Fundação de Amparo à Pesquisa do Estado do Rio Grande do Sul) e ao Instituto Federal de Educação, Ciência e Tecnologia Farroupilha.

\section{REFERÊNCIAS}

Aguiar, R. W. S.; Brito, D. R.; Ootani, M. A.; Fidelis, R. R.; Peluzio, J. N.; Efeito do dióxido do carbono, temperatura e armazenamento sobre sementes de soja e micoflora associada. Revista Ciência Agronômica, v.43, p.554-560, 2012.

Alborch, L.; Bragulat, M. R.; Abarca, M. L.; Cabañes, F. J.; Effect of water activity, temperature and incubation time on growth and ochratoxin a production by Aspergillus niger and Aspergillus carbonarius on maize kernels. International Journal of Food Microbiology; v.147, n.01, p.53-57, 2011.

Alencar, E. R.; Faroni, L. R. D.; Lacerda Filho, A. F.; Peternelli, L. A.; Costa, A. R.; Qualidade dos grãos de soja armazenados em diferentes condições. Revista Brasileira de Engenharia Agrícola e Ambiental, v.13, n.5, p.606-613, 2009.

ASAE - American Society of Agricultural Engineers. Moisture measurement - Unground grain and seeds, St. Joseph: ASAE, 2000. 563p.

Brackmann, A.; Neuwald, D. A.; Ribeiro, N. D.; Freitas, S. T.; Conservação de três genótipos de feijão (Phaseolus vulgaris L.) do grupo carioca em armazenamento refrigerado e em atmosfera controlada. Ciência Rural, v.32, p.911-915, 2002.

Brasil. Mistério da Agricultura, Pecuária e Abastecimento. Instrução Normativa N 11, de 15 de março de 2007. Regulamento Técnico da Soja. Diário Oficial da União. 16.05.2007, Brasília, DF.

Brasil. Ministério da Agricultura, Pecuária e Abastecimento. Regras para análise de sementes / Ministério da Agricultura, Pecuária e Abastecimento. Secretaria de Defesa Agropecuária. Brasília: MAPA/ACS, 2009, 399p.

Carneiro, L. M. T. A.; Biagi, J. D.; Freitas, J. G.; Carneiro, M. C.; Felício, J. C.; Diferentes épocas de colheita, secagem e armazenamento na qualidade de grãos de trigo comum e duro. Bragantia, v.64, p.127-137, 2005.

Carvalho, M. L. M.; Silva, W. R.; Refrigeração e qualidade de sementes de milho armazenadas em pilhas com diferentes embalagens. Revista Agropecuária Brasileira, v.9, p.1319-1332, 1994.

Costa, A. R.; Faroni, L. R. D.; Alencar, E. R.; Carvalho, M. C. S; Ferreira, L. G.; Qualidade de grãos de milho armazenados em silos bolsa. Revista Ciência Agronômica, v.41, p.200-207, 2010.

Dueñas, M.; Hernández, T.; Lamparski, G.; Estrella, I.; Muñoz, R.; Bioactive Phenolic Compounds of Soybean (Glycine max cv. Merit): Modifications by Different Microbiological Fermentations. Polish Journal of Food and Nutrition Sciences, v.62, n.4, p.241-250, 2012.

Faroni, L. R. A.; Fatores que influenciam a qualidade dos grãos armazenados. Viçosa, MG. 1998 p.115. ISTA. INTERNATIONAL SEED TESTING ASSOCIATION; Determination of other seeds by number. In: International rules for seed testing. ed. 2008. Bassersdorf, 2008, c.4, p.4.1-4.3 
Faroni, L. R. A.; Barbosa, G. N. O.; Sartori, M. A.; Cardoso, F. S.; Alencar, E. R.; Avaliação qualitativa e quantitativa do milho em diferentes condições de armazenamento. Engenharia na Agricultura, v.13, p.193-201, 2005.

Faroni, L. R. A.; Alencar, E. R.; Paes, J. L.; Costa, A. R.; Roma, R. C. C.; Armazenamento de soja em silos tipo bolsa. Engenharia Agrícola, v.29, n.1, 2009.

Lazzari, F. A.; Umidade, fungos e micotoxinas na qualidade de sementes, grãos e rações. Curitiba, Edição do autor, 134 p., 1997.

Kumar, V.; Rani, A.; Dixit, A. K.; Pratap, D.; Bhatnagar, D.; A comparative assessment of total phenolic content, ferric reducing-anti-oxidative power, free radical-scavenging activity, vitamin $\mathrm{C}$ and isoflavones content in soybean with varying seed coat colour. Food Research International, v.43, n.1, p.323-328, 2010.

Paraginski, R.T.; Rockenbach, B.A.; Santos, R.F.; Elias, M.C.; Oliveira, M.; Qualidade de grãos de milho armazenados em diferentes temperaturas. Revista Brasileira de Engenharia Agrícola e Ambiental, v.19, n.4, p.358-363, 2015.

Park, C. E.; Kim, Y. S.; Park, K. J.; Kim, B. K.; Changes in physicochemical characteristics of rice during storage at diferente temperatures. Journal of Stored Products Research, v.48, p.25-29, 2012.

Perez-Garcia, F.; Gonzalez-Benito, M. E.; Seed germination of five Helianthemum species: Effect of temperature and presowing treatments. Journal of Arid Environments, v.65, p.688-693, 2006.

Reed, C.; Doyungan, S.; Ioerger, B.; Getchell, A.; Response of storage molds to different initial moisture contents of maize (corn) stored at $25^{\circ} \mathrm{C}$, and effect on respiration rate and nutrient composition. Journal of Stored Products Research, v.43, p.443-458, 2007.

Rehman, Z. U.; Habib, F.; Zafar, S. I.; Nutritional changes in maize (Zea mays) during storage at three temperatures. Food Chemistry, v.77, p.197-201, 2002.

Rigueira, R. J. A.; Lacerda Filho, A. F.; Volk, M. B. S.; Avaliação da qualidade do feijão armazenado em ambiente refrigerado. Alimentos e Nutrição, v.20, p.649-655, 2009.

Rodriguez, J.C.; Bartosik, R.E.; Malinarich, H.D.; Exilart, J.P.; Nolasco, M.E.; IP short time storage of Argentine cereals in silobags to prevent spoilage and insect. In: International Quality Grains Conference, 2004, Indianapolis. Proceedings... West Lafayette: Purdue University, 2004. 1-15

Santos, C. M. R.; Menezes, N. L.; Villela, F. A.; Alterações fisiológicas e bioquímicas em sementes de feijão envelhecidas artificialmente. Revista Brasileira de Sementes, v.26, p.110-119, 2004.

Silva, J. S.; Afonso, A. D. L.; Lacerda Filho, A. F.; Secagem e armazenagem de produtos agrícolas. In: Silva, J. S. Pré-processamento de produtos agrícolas. Juiz de Fora: Instituto Maria, p.395-462, 1995.

Sravanthi, B.; Jayas, D. S.; Alagusundaram, K.; Chelladurai, V.; White, N.D.G.; Effect of storage conditions on red lentils. Journal of Stored Products Research, v.53, p.48-53, 2013.

Stanojevic, S. P.; Barac, M. B.; Pesic, M. B.; Vucelic-Radovic, B. V.; Assessment of soy genotype and processing method on quality of soybean tofu. Journal of Agricultural and Food Chemistry, v.59, n.13, p.7368-7376, 2011.

Tang, S.; Tekrony, D. M.; Egli, D. B.; Cornelius, P. L. Survival characteristics of corn seed during storage: II. Rate of seed deterioration. Crop Science, v.39, p.1400-1406, 1999.

Zain, M.E.; Impact of mycotoxins on humans and animals. Journal of Saudi Chemical, v.15, p.129$144,2011$. 